\title{
The Role of social support and need for achievement on psychological well-being of below the knee amputees.
}

\author{
Olugbemi Olukolade ${ }^{1}$, Tolulope .I. Alao ${ }^{2}$, Adesoji .A. Adebisi ${ }^{3}$ \\ ${ }^{1}$ (Clinical psychology Unit, Family Medicine department, University College Hospital, Ibadan, Oyo-state, \\ Nigeria) \\ ${ }^{2}$ (clinical Nursing department, University College Hospital, Ibadan, Oyo-state, Nigeria) \\ ${ }_{3}^{3}$ (Clinical psychology Unit, Family Medicine department, University College Hospital, Ibadan, Oyo-state, \\ Nigeria)
}

\begin{abstract}
Below the knee amputation negatively impacts psychological states despite its well documented impacted on self concept. People with below the knee amputation experience lots of problems from inability to perform activities of daily living to problems with socialization and reintegration into pre-morbid functionality leading to shattered states of the mind about life, people and future. Unfortunately, the numbers of below the knee amputees are steadily increasing, due to high use of motorbikes and increase of in lifestyle illness such as cancer, diabetes and vascular diseases. This study investigated 78 below the knee amputees, which were conveniently drawn and investigated on their socio-demographics, perceived social support, need for achievement and psychological well being, the result showed that perceived social support and need for achievement determines psychological well in below the knee amputees $(t=1.239, t=-12.506), p<0.5$, while the gender, marital status and level of education does not. A coordinated social support and purpose at pre and post operative stages might significantly reduce psychological distress in amputees.
\end{abstract}

Keywords: perceived social support, need for achievement, below the knee amputees, psychological wellbeing.

\section{Introduction}

\section{Introduction}

People with below the knee amputation face many challenges post operatively despite healthcare provision efforts in various parts of the world. These challenges range from physical to emotional to psychosocial issues and these issues affect the psychological well being of people with below the knee amputation. The number of people requiring amputation has increased significantly with the rise in diseases that contribute to amputation such as vascular diseases, diabetes and tumors. There are an estimated 135 million people with diabetes in the world. This can result in ulcers and infection that may lead to amputation. In industrialized countries like the United States and Denmark, disease causes approximately $65 \%$ of all amputations performed each year. However, this is not true of many developing countries like Nigeria where trauma is the main cause of amputation, especially with motorbike been one of the major means of transportation despite its inappropriateness on many of the busy roads and the burden of lifestyle diseases such as diabetes, tumors or vascular diseases are not lessened in this clime but on a gradual increase.

Below the knee amputation is performed for a variety of reasons that range from disease to trauma (Wong, 2005; Spichler 2001; The Global Lower Extremity Study, 2000; Van Houtum et al, 1996; Engstrom \& Van de Ven, 1999). Below the knee amputation results in a wide range of outcomes; amputation generally results in poor physical function, physical role performance, social function, vitality, general health, and more pain compared to population norms (Eiser et al, 2001). Everyday competence tends to decrease with age for both males and females following below the knee amputation but male usually have better physical function than females (Eiser et al,) Amputation impact negatively on mobility, emotion, sleep, pain and social and psychological function; people with a below the knee amputation experience problems with activities of daily living including household chores, hobbies and social relationships (Pell et al, 1993). Some people with below the knee amputation can be mobile around their home, while others may require a walking aid or use a wheelchair. People with a below the knee amputation end up with decreased speed, decreased range of motion of the hip and knee, poor vertical ground reaction force, increased amplitude and periods of muscle activation, short single support on stance leg (amputated leg), small stance, instability in stance and decreased proprioception (Vickers et al, 2008). This may thus result in functional limitation because overall they have a somewhat reliance on others for their movement from a place to the other.

Psychological state of amputees is usually shattered, leading to a state of psychological un-wellness. Psychological well-being is a state of complete wellness in the mental status. Below the knee amputees 
experience a lot of negative feelings and expectations which are sometimes overt or covert. People with below the knee amputation experience anxiety and depression following amputation of the lower extremity, sometimes they experiences low self esteem, loss of interest in life and can become suicidal.. These psychological reactions correlate significantly with age and marital status, and there is no correlation with level of amputation, mode of ambulation and indication for amputation (Mosaku et al, 2009).

Social support and the quality of such support had been touted to have significant impact of the effect of the psychological sequel of amputation. It is believed that people who have a stable relationship, caring partner or spouse, a career path, family with strong support and strong social affiliation will have lower negative effect of amputation. Several studies indicated that supportive contacts correlate negatively with symptoms and psychological disorder such as stress, depression and other psychiatric disorder, and positively correlate with physical and mental health. A study by Nahid \& Sarkis (1994) for example found that social support protects people in life crisis such as bereavement, illness, and other major stress, and moderates the effect of stressors on psychological well being.

It is believed that social support is very much important for individuals in their life. Deficits in social support have been shown to be related to many psychological problems such as depression, loneliness, and anxiety (Eskin, 2003). Elliot and Gramling (1990) found that social support helps the amputees to lessen depression, anxiety, and stress.

Secondly; social support has also been recognized to have significant impact on the achievement of the amputees. Since family and friends are the individuals' first source of reference, supports from these two sources have been found to give a significant influence on psychological well being (Steinberg \& Darling, 1994; Cutrona, 1994). The support received by the amputees could help to decrease their psychological problems since they feel that someone is there to help them, thus helping them to perform well in life.

With regard to the above mentioned background and problem statement the following research questions are raised:

1.1. What is the level of Psychological well being among below the knee amputees in health centers in Ibadan? 1.2. How will social support influence psychological well being among below the knee amputees in health centers in Ibadan?

1.3. Will need for achievement play significant role on the psychological well being of below the knee amputees in health centers in Ibadan?

This study explored the effect of social support on psychological well being among below the knee amputees in health centers in Ibadan. Also, the differences in psychological well being of below the knee amputee between the male and female gender.

\subsection{Participants and procedure}

\section{Method}

The study was carried out in Ibadan metropolis; the hospitals include: Odunlakin specialist hospital, Sunnydale orthopaedics hospital and University College Hospital Ibadan. These hospitals have adequate number of attendees who are below the knee amputees who come for treatment and check-up. The researchers obtained permission from clients and family members and adequate information where provided about the study. After providing consent and assent, amputees completed the questionnaires; there was no financial reward for the part6icipation. Participants were 16-69 years old $(\mathrm{N}=78) .52(66.7 \%)$ were male, $26(33.3 \%)$ female. Marital status of respondents shows that $21(26.9 \%)$ are single, $45(57.7 \%)$ are married, $9(11.5 \%)$ are divorced while 3 $(3.8 \%)$ are widowed.

\section{Measures}

3.1. Demographics. Demographic information included age, gender, educational qualification, marital status, religion and ethnic group.

3.2. Perceived social support. The Multidimensional Scale of Perceived Social Support (MSPSS). The MSPSS is a self-report likert-type measure designed to measure perceived support from friends, family members and significant others. (Zimet, Powell, Farley, Werkman, \& Berko, 1990). The MSPSS provides assessment of three sources of support: family (FA), friends (FR), and significant other (SO). With four items geared to measure each of $\mathrm{t}$ he mentioned subscales. Items 3, 4,8,11 measures Family, Items 6, 7,9,12 measures Friend, Items 1, 2, 5, 10 measures Significant other.

3.3. Need for Achievement. The Need for Achievement scale with 16 -item scale from the Personality Research Form, Stronger agreement reflects high achievement needs, while low agreement reflects lower levels of achievement needs. Items 9 through 16 are recoded and a single score for each participant is obtained by 
summing up responses on all the items. Sample items from this scale include: "I often set goals that are very difficult to reach", and "I try to work just hard enough to get by."

3.4. Psychological Well-being. The Ryff's scale of Psychological well being is a 54 item inventory consisting of statements reflecting the sis areas of psychological well-being: autonomy, environmental mastery, personal growth, positive relations with others, purpose in life, and self-acceptance. Respondents rate statements on a scale of 1 to 5, with 1 indicating strong disagreement and 5 indicating strong agreement. Some of the items found in the scale are: 'I have confidence in my opinions, even if they are contrary to the general consensus', 'In general, I feel I am in charge of the situation in which I live. I think it is important to have new experiences that challenge how you think about yourself and the world.

\section{Data analysis}

Statistical Package for Social Sciences software, release 17 (SPSS). At $\mathrm{P}<0.05$ level of confidence was considered significant. Independent t-test statistics and the multiple regression analysis.

\subsection{Social support and psychological well-being of amputees}

\section{Results}

Social support has significant influence on psychological well-being, with a significant difference found in the mean with higher social support with a mean of $(\bar{X}=135.42)$ and amputees with lower social support with a mean of $(\bar{X}=129.77)$, implying that participants with high social support reported higher psychological well-being than low social support counterpart.(see table 5.1)

\section{Table 5.1}

Social support and psychological well-being of amputees

\begin{tabular}{|l|l|l|l|l|l|l|l|}
\hline & $\begin{array}{l}\text { Social } \\
\text { support }\end{array}$ & N & $\overline{\boldsymbol{x}}$ & SD & df & $\mathbf{t}$ & P \\
\cline { 2 - 9 } $\begin{array}{l}\text { Psychological well- } \\
\text { being }\end{array}$ & Low & 36 & 129.77 & 32.07 & \multirow{2}{*}{76} & -1.239 & $<.05$ \\
\cline { 2 - 9 } & High & 42 & 135.42 & 28.98 & & & \\
\hline
\end{tabular}

\subsection{Need for achievement and psychological well-being of amputees}

Need for achievement has significant influence on psychological well-being with below the knee amputees who had higher need for achievement had higher psychological well being with a significantly higher mean with mean $(\bar{X}=155.97)$ for those with high achievement and a mean of $(\bar{X}=106.62)$ for those with low need for achievement and with a mean difference of -4.93 . This implies that participants with high need for achievement reported higher psychological well-being than low need for achievement counterpart.

Table 5.2: Need for achievement on psychological well-being

\begin{tabular}{|c|c|c|c|c|c|c|c|}
\hline \multirow{3}{*}{$\begin{array}{l}\text { Psychological } \\
\text { well-being }\end{array}$} & $\begin{array}{l}\text { Need for } \\
\text { achievement }\end{array}$ & $\mathbf{N}$ & $\bar{x}$ & SD & df & $\mathbf{t}$ & $\mathbf{P}$ \\
\hline & Low & 40 & 106.62 & 12.26 & \multirow[t]{2}{*}{76} & \multirow[t]{2}{*}{-12.506} & \multirow[t]{2}{*}{$<.01$} \\
\hline & High & 38 & 155.97 & 21.55 & & & \\
\hline
\end{tabular}

\subsection{Gender and psychological well-being of below the knee amputees}

Gender has no significant influence on psychological well-being $(t=-1.070 ; d f=76 ; p>0.05)$. This can be observed in the mean where male participants score $(\bar{X}=128.07)$ on psychological well-being and female participants score ( $\bar{X}=135.84$ ) with a mean difference of -7.76 was not significant. 
Table 5.3: Gender on psychological well-being

\begin{tabular}{|l|l|l|l|l|l|l|l|}
\hline \multirow{4}{*}{$\begin{array}{l}\text { Psychological } \\
\text { well-being }\end{array}$} & Gender & $\mathbf{N}$ & $\overline{\boldsymbol{x}}$ & SD & df & $\mathbf{t}$ & $\mathbf{P}$ \\
\cline { 2 - 8 } & Male & 52 & 128.07 & 29.43 & \multirow{2}{*}{76} & -1.070 & $>.05$ \\
\cline { 2 - 5 } & Female & 26 & 135.84 & 31.80 & & & \\
\hline
\end{tabular}

\subsection{Social predictors of psychological well-being in below the knee amputees}

The social predictors used are age, level of education, marital status as predictors of psychological well-being, however, age, level of education and marital status did not jointly predict psychological well being among below the knee amputees. Also, the independent influence of the predictor variables shows that neither age, level of education nor marital status predicted psychological well-being independently.

Table 5.4: Age, marital status and level of education in prediction of psychological well-being

\begin{tabular}{|l|l|l|c|l|l|l|l|}
\hline Predictor & Beta $(\beta)$ & t-value & Sig & R & $\mathbf{R}^{2}$ & F & P \\
\hline Age & -0.106 & -0.708 & $>.05$ & & & & \\
\hline Level of Education & -0.085 & -0.744 & $>.05$ & 0.174 & 0.030 & 0.770 & $>0.05$ \\
\hline Marital Status & -0.054 & -0.361 & $>.05$ & & & & \\
\hline
\end{tabular}

\section{Discussion}

To our knowledge, issues about below the knee amputees had always focused on emotional reactions and subsequent health status rather than specific psychological health and its determinants. Specifically, this study assessed the effect of social support on psychological well-being, evaluated the influence of need for achievement on psychological well-being, examined gender difference in psychological well-being and finally explored the relevance of marital status, age of participant and level of education on psychological well-being of below the knee amputees.

The study predicted that below the knee amputees which are relatively higher on perceived social support will have better psychological well-being, this was based on the belief that social support will cushion the effect of negative ruminative thoughts about the amputation and its antecedent limitations, this view was corroborated with Table1, these was significantly higher mean for amputees with greater family significant others. This reflected the views of Calvete \& Connor-Smith, 2006, that Support from family and friends have been found to reduce the impact of psychological problems.

Again the study predicted that need for achievement will have significance in the development of psychological well-being, this is hinged on the conception that determination or belief of ability or need to still do things in life will determine belief of limitation or not. The result showed that the higher the need for achievement the higher the psychological well while the lower the need for achievement the lower the psychological well-being. Increasing psychological well being may be useful for persons of below the knee amputation with high need for achievement because it helps them gain appropriate attitude in life and set more challenging yet attainable targets which will in turn boost their sense of psychological well being.

Gender differences was, however, not significant in the prediction of psychological well being of the amputees, this can be observed in table 3 with the mean of male participants score $(\bar{X}=128.07)$ on psychological well-being and female participants score $(\bar{X}=135.84)$ with a mean difference of -7.76 was not significant.

There was also the prediction of age, educational level and marital status jointly predicting psychological well-being but the result showed in table 4 , that neither age, level of education nor marital status predicted psychological well-being independently $(\beta=-0.106, t=-0.708, p>05),(\beta=-0.085, t=-0.744, p>.05)$ and $(\beta=-0.054$, $\mathrm{t}=-0.361, \mathrm{p}>.05)$, respectively.

\section{Conclusion}

The study underscored the importance of emotional support from the family, friends and significant others in the pursuit of psychological well-being. people differ in their level of psychological well being based on their level of need for achievement, serving as a motivation and as a psychological drive, need for achievement is positively related and can predict psychological well being. social support which is probably one of the features of positive psychology and psychological well-being can be of immense help to greater number of people especially people who undergo stigmatization, physical, and psychological trauma and most times financial distress 
However, it is recommended that the families, friends and significant others in the life of below the knee amputees should rally round them and provide the much needed social support. Psycho-education aimed at impacting knowledge on how social support could help below knee amputees to improve their psychological well being and cope with any psychological disturbances should be provided by the health centers. Prior to amputation surgery, It is recommended that information should be provided to them to reduce the person's and the family's anxiety, obtain cooperation in the treatment program, and to help the person with an amputation to adjust to his new condition. The relatively small sample size, the number of participants used in this study was a limitation to its generalisability. Also, there was no comparative study or control group in this study. Finally, the study is also limited in that it was carried out among below the knee amputees in the particular group which could have implications for specific psychological traits in the population i.e. all been relatively educated that are quite different from amputees in other environments or those that are not seeking medical treatment.

\section{References}

[1] Wong, M. W. (2005). Lower extremity amputation in Hong Kong, Hong Kong Medical Journal, 11(3): 147-152

[2] Spichler, E. R. (2001). Capture-recapture method to estimate lower-extremity amputation rates in Rio de Janeiro, Brazil, Pan American Journal of Public Health, 10(5): 334-340

[3] The Global Lower Extremity Amputation (GLEA) Study Group, (2000). Epidemiology of lower extremity amputation in centers in Europe, North America and East Asia, British Journal of Surgery, 87(3): 328-37

[4] Van Houtum, W. H, Lavery, L. A., \& Harkless, L. B. (1996). The impact of diabetes-related lower-extremity amputations in the Netherlands, Journal of Diabetes and its Complications, 10 (6): 325-330

[5] Engstrom, B., \& Van de Ven, C. (1999) therapy for amputees, 3rd edition, churchill livingstone page 1-96.

[6] Eiser, C., Darlington, A. S., \& Grimer, R. (2001) Quality of life implications as a consequence of surgery: limb salvage, primary and secondary amputation, Sarcoma, 5: 189-195

[7] Pell, J. P., Donnan, P. T., Fowkes, F. G., \& Ruckey, C. V. (1993) Quality of life following lower limb amputation for peripheral arterial disease, European Journal of Vascular Surgery, 7:448-451

[8] Vickers, D. R., Palk, C., McIntosh, A. S., \& Beatty, K. T, (2008) Elderly transtibial unilateral amputee on an incline walkway: a biomechanical analysis. Gait \& Posture, 27: 518-529

[9] Mosaku, K. S., Akinyoola, A. L., Fatoye, F. O., \& Adegbehingbe, O. O. (2009) Psychological reactions to amputation in a Niger ian sample of amputees of General Hospital, Journal of Psychiatry, 31, (1): 20-24

[10] Nahid, O.W. \& Sarkis, E. (1994). Types of social support: relation to stress and academic achievement among prospective teachers. Canadian Journal of Behavioral Science, 26, (1),1.

[11] Elliot, T.R., \& Gramling, S.E. (1990). Personal assertiveness and the effects of social support among college students. Journal of Counseling Psychology, 37,427-436.

[12] Eskin, M. (2003). Self-reported assertiveness in Swedish and Turkish adolescents: A cross-cultural comparison. Scandinavian Journal of Psychology, 44, 7-12.

[13] Steinberg, L, \& Darling, N. (1994). The broader context of social influence in adolescence. In Silbereisen, R.K. \& Todt, E. (Eds.), Adolescence in Context: The Interplay of Family, School, Peers, and Work in Adjustment. (New York: Springer-Verlag Inc. 1994)

[14] Cutrona, C. E. (1994). Perceived parental social support and academic achievement: An attachment theory perspective. Journal of 'Personality and Social Psychology, 66(2), 369-378.

[15] Calvete, H. \& Connor-Smith, J.K. (2006). Perceived social support, coping, and symptoms of distress in American and Spanish students. Journal of Anxiety, Stress, and Coping, 19(1), $47-65$ 